\title{
Assessment and risk classification protocol for patients in emergency units ${ }^{1}$
}

\author{
Michele de Freitas Neves Silva ${ }^{2}$ \\ Gabriela Novelli Oliveira ${ }^{3}$ \\ Aline Maino Pergola-Marconato ${ }^{4}$ \\ Rafael Silva Marconato ${ }^{5}$ \\ Eliete Boaventura Bargas ${ }^{6}$ \\ Izilda Esmenia Muglia Araujo ${ }^{7}$
}

Objective: to develop, validate the contents and verify the reliability of a risk classification protocol for an Emergency Unit. Method: the content validation was developed in a University Hospital in a country town located in the state of Sao Paulo and was carried out in two stages: the first with the individual assessment of specialists and the second with the meeting between the researchers and the specialists. The use of the protocol followed a specific guide. Concerning reliability, the concordance or equivalent method among observers was used. Results: the protocol developed showed to have content validity and, after the suggested changes were made, there were excellent results concerning reliability. Conclusion: the assistance flow chart was shown to be easy to use, and facilitate the search for the complaint in each assistance priority.

Descriptors: Triage; Emergency Nursing; Emergency Medical Services.

\footnotetext{
${ }^{1}$ Paper extracted from Master's Thesis "Triage protocol of an emergency unit" presented to Faculdade de Ciências Médicas, Universidade Estadual de Campinas, Campinas, SP, Brazil.

2 MSc, RN, Hospital de Clínicas, Universidade Estadual de Campinas, Campinas, SP, Brazil.

${ }^{3}$ RN, Hospital Universitário, Universidade de São Paulo, São Paulo, SP, Brazil.

${ }^{4}$ Doctoral student, Faculdade de Enfermagem, Universidade Estadual de Campinas, Campinas, SP, Brazil.

${ }^{5}$ Master's student, Faculdade de Enfermagem, Universidade Estadual de Campinas, Campinas, SP, Brazil. RN, Hospital de Clínicas, Universidade Estadual de Campinas, Campinas, SP, Brazil.

${ }^{6}$ MSc, RN, Hospital de Clínicas, Universidade Estadual de Campinas, Campinas, SP, Brazil.

${ }^{7} \mathrm{PhD}$, Professor, Faculdade de Enfermagem, Universidade Estadual de Campinas, Campinas, SP, Brazil.
}

Corresponding Author:

Rafael Silva Marconato

Rua Pedro João Walter Vannucci, 516

Residencial Vitória Ropole

Caixa Postal: 6584

CEP: 13082-826, Campinas, SP, Brasil

E-mail: rafamarcc@yahoo.com.br
Copyright (c) 2014 Revista Latino-Americana de Enfermagem This is an Open Access article distributed under the terms of the Creative Commons Attribution Non-Commercial License (CC BY-NC).

This license lets others distribute, remix, tweak, and build upon your work non-commercially, and although their new works must also acknowledge you and be non-commercial, they don't have to license their derivative works on the same terms. 


\section{Introduction}

Emergency services represent an important part of the path into the healthcare system, since part of the population seeks these units to solve less complex issues, causing these services to be overcrowded. This reality can be seen internationally and in Brazil(1-2).

To meet this demand for emergency services ${ }^{(3-4)}$, one of the actions of PNH and Qualisus includes the implementation of reception and selection of patients in hospitals, prioritizing the provision of care according to the severity of the case and no longer by order of arrival ${ }^{(1)}$, and which identifies patients in emergency conditions, increases users' satisfaction, decreases overcrowding and organizes care flow(5).

The selection of patients was originated in the army, in the battle fields, in 1800. The formal concept of patient selection was introduced in the Emergency Departments in the United States in the late 50s, when the number of patients seeking these services increased significantly ${ }^{(6)}$

Given the above, and taking into account the need for implementation of risk classification in the Brazilian healthcare units, the Federal Nursing Board determined, in Resolution number 423/2012, that risk classification is the sole responsibility of nurses who need to have the knowledge, skills and abilities to ensure technical and scientific accuracy in this procedure ${ }^{(7)}$. Only few institutions have protocols, and publications about this subject are rare.

The aims of this study were to develop, validate the contents and verify the reliability of a risk classification protocol for a Referred Emergency Unit (REU) of a University Hospital.

\section{Method}

This is a quantitative study, developed in a REU of a University Hospital located in a country town in the state of Sao Paulo, which provides care to an average of 400 patients per day. The study was divided into five stages: profile assessment/demand of patients in the unit; assessment of the risk classification protocol found in the literature; development of the risk classification protocol according to the profile of the population assisted; content validation and verification of the protocol reliability. The first stage was covered by another article, in which a retrospective survey of the population profile and of the care demand was carried out, based on the data found in the assistance records of the Unit( ${ }^{(8)}$.
For the assessment of risk classification protocols stage, the following protocols were analyzed: Manchester/ England(9), AST/Australia(10), CTAS/Canada(11), ESI/United States ${ }^{(12)}$, Reception and Risk Classification of the Hospital Conceição/ Porto Alegre-RS(4), Reception Project of the Hospital Municipal Mário Gatti/Campinas-SP(13), Hospital Odilon Behrens/ Belo Horizonte-MG ${ }^{(14)}$ and the Reception with Assessment and Risk Classification Protocol of the MS/ Brazil(15)

Concerning the development of the risk classification protocol, this was divided into four care priorities: red (Group 1), yellow (Group 2), green (Group 3), and blue (Group 4). Each one of the groups has the main complaints, signs and symptoms of patients and was subdivided into items, as presented in Figure 1 (Group 1), Figure 2 (Group 2) and Figure 3 (Groups 3 and 4). The same complaint can fit into more than one group, according to nurses assessment. The original flow chart format is shown in the masters dissertation of one of the authors.

As for the content validation stage, the protocol was submitted to the assessment of seven specialists. For the assessment, a guide was used with the protocol items and the assessment criteria: organization, coverage, objectivity and relevance. Upon return of the assessment, the compilation of the answers and suggestions was performed and then a meeting between the specialists committee and the researchers was held in which suggestions for proposed amendments were presented and the participants expressed their opinions in relation to the items until reaching a consensus.

At the verification of reliability stage, the Concordance or Equivalent method was used, and four nurses of the Unit participated in it. For their inclusion, it was required at least one year experience with risk classification in the unit and acceptance to participate in the study. Before the start of the application of the protocol, one of the researchers did the training of each nurse individually, clarified their doubts and carried out the practical application of the protocol.

The application of the protocol was done according to a data collection guide developed by the researchers. During the collection, the observers (obs) filled out the guide, as well as the protocol, in which they marked the complaint that determined the classification and the sub-items of this complaint. In the description of the reliability assessment, the researcher was called observer-researcher and the nurses obs-1, 2, 3 and 4. In addition to these instruments, an assistance flow chart was given to the nurses to help with the choice of priority in the assistance. 


\begin{tabular}{|c|c|c|c|}
\hline \multicolumn{4}{|c|}{ Group 1 (Red) - Patients sent to the Emergency Room for immediate treatment, due to imminent death risk } \\
\hline 1.1 & Alteration in the mental condition & 1.6 & Chest pain \\
\hline 1.1.1 & Lack of response to stimulus (verbal, painful, tactile) & 1.6 .1 & Precordial pain with tightness and/or burning sensation \\
\hline 1.2 & Chronic headache & 1.6 .2 & Pain irradiation to upper limbs \\
\hline 1.2 .1 & Sudden onset and strong intensity & 1.6 .3 & $\mathrm{BP}<100 / 70 \mathrm{mmHg}$ or $>140 / 90 \mathrm{mmHg}$ \\
\hline 1.2 .2 & Convulsive crisis event & 1.6 .4 & $\mathrm{CF}>90 \mathrm{bpm}$ or $\mathrm{CF}<60 \mathrm{bpm}$ \\
\hline 1.2 .3 & Acute motor deficit $<48 \mathrm{~h}$ & 1.6 .5 & Dyspnea \\
\hline 1.2.4 & Alteration in the level of consciousness & 1.6.6 & $\mathrm{RF}>20 \mathrm{rpm}$ \\
\hline 1.2 .5 & Presence of $\mathrm{BP}>140 / 90 \mathrm{mmHg}$ & 1.6 .7 & Pulse asymmetry \\
\hline 1.2 .6 & $\mathrm{CF}<60 \mathrm{bpm}$ & 1.6 .8 & Age $>60$ years or previous history of coronary artery disease, 5 \\
\hline 1.2 .7 & Neck stiffness, vomiting & 1.7 & Fever \\
\hline 1.3 & $\begin{array}{l}\text { Motor deficit (muscular weakness face or limbs unilateral or } \\
\text { bilateral) }\end{array}$ & 1.7 .1 & $\mathrm{~T}>37.8^{\circ} \mathrm{C}$ at the time of appointment \\
\hline 1.3.1 & Sudden onset (<48h) & 1.7 .2 & $\mathrm{BP}<100 / 70 \mathrm{mmHg}$ \\
\hline 1.4 & Dyspnea & 1.7 .3 & CF $>100 \mathrm{bpm}$ \\
\hline 1.4 .1 & Moderate to intense respiratory discomfort & 1.7 .4 & Alteration in the level of consciousness \\
\hline 1.4 .2 & Cyanosis & 1.7 .5 & $\mathrm{RF}>25 \mathrm{rpm}$ \\
\hline 1.4 .3 & $\begin{array}{l}\text { Use of accessory muscles (intercostal retractions, suprasternal } \\
\text { retraction or beating of wings of nose) }\end{array}$ & 1.7.6 & Dyspnea \\
\hline 1.4 .4 & Respiratory rate $>20 \mathrm{rpm}$ & 1.7 .7 & Immunosupression \\
\hline 1.4 .5 & Difficulty speaking & 1.8 & Hyperglycemia \\
\hline 1.4.6 & $\mathrm{T}^{\circ}>37.8^{\circ} \mathrm{C}$ or $\mathrm{T}^{\circ}<35^{\circ} \mathrm{C}$ & 1.8 .1 & $\begin{array}{l}\text { Associated with the alteration in the level/content of } \\
\text { consciousness }\end{array}$ \\
\hline 1.4 .7 & Alteration in the level of consciousness & 1.9 & SBP $>140 \mathrm{mmHg}$ or DBP $>120 \mathrm{mmHg}$, associated with: \\
\hline 1.4 .8 & Oxygen saturation $<95 \%$ & 1.9 .1 & Alteration in the level of consciousness \\
\hline 1.4 .9 & $\mathrm{CF}>100 \mathrm{bpm}$ & 1.9 .2 & Acute motor deficit (paralysis, paresis) \\
\hline 1.5 & Abdominal pain & 1.9 .3 & Chest pain \\
\hline 1.5 .1 & $\mathrm{BP}<100 / 70 \mathrm{mmHg}$ or $>140 / 90 \mathrm{mmHg}$ & 1.9 .4 & Dyspnea \\
\hline 1.5 .2 & $\mathrm{CF}>100 \mathrm{bpm}$ & 1.10 & Hypoglycemia \\
\hline 1.5.3 & $\mathrm{T}^{\circ}>37.8^{\circ} \mathrm{C}$ at the time of appointment & 1.10 .1 & $\begin{array}{l}\text { Associated with the alteration in the level/content of } \\
\text { consciousness }\end{array}$ \\
\hline 1.5 .4 & History of abdominal trauma (close, firearms or stabbing) & 1.11 & Cardiorespiratory arrest \\
\hline & & 1.11 .1 & Absence of carotid pulse ( 5 to 10 seconds) \\
\hline & & 1.11 .2 & Absence of breathing movements \\
\hline & & 1.11 .3 & Unconsciousness \\
\hline
\end{tabular}

Figure 1 - Risk classification protocol for Group 1 (Red). Campinas, SP, Brazil, 2010

\begin{tabular}{|c|c|c|c|}
\hline \multicolumn{4}{|c|}{$\begin{array}{l}\text { Group } 2 \text { (Yellow) - Patients who should be assessed by a doctor in the period between } 15 \text { and } 30 \text { minutes } \\
\text { after the nurse's assessment because they present signs and symptoms that could become more serious }\end{array}$} \\
\hline 2.1 & Alteration in the SSVV and symptoms not previously specified & 2.8 & Chest pain \\
\hline 2.1 .1 & $\mathrm{BP}>150 / 100 \mathrm{mmHg}$ or $\mathrm{BP}<100 / 60 \mathrm{mmHg}$ & 2.8 .1 & Family history of stroke or myocardial infarction \\
\hline 2.1 .2 & $\mathrm{CF}>100 \mathrm{bpm}$ or $\mathrm{CF}<60 \mathrm{bpm}$ & 2.9 & Fever \\
\hline 2.1 .3 & $\mathrm{RF}>20 \mathrm{rpm}$ & 2.9 .1 & $\mathrm{~T}>37.8^{\circ} \mathrm{C}$ at the time of the appointment \\
\hline 2.1 .4 & $\mathrm{~T}^{\circ}>37.8^{\circ} \mathrm{C}$ at the time of the appointment & 2.10 & High or low gastrointestinal bleeding \\
\hline 2.2 & Alteration in the mental condition & 2.10 .1 & History of rectal bleeding, melena or hematemesis \\
\hline 2.2 .1 & Alteration in the level of consciousness & 2.10 .2 & $\mathrm{BP}<100 / 70 \mathrm{mmHg}$ \\
\hline 2.3 & Chronic headache & 2.10 .3 & $\mathrm{CF}>100 \mathrm{bpm}$ \\
\hline 2.3 .1 & $\begin{array}{l}\text { Strong intensity pain, disabling, progressive, not responsive to } \\
\text { medication }\end{array}$ & 2.10 .4 & Alteration in the level of consciousness \\
\hline 2.4 & Diarrhea & 2.10 .5 & $\begin{array}{l}\text { History of cirrhosis or liver or colon cancer, use of non- } \\
\text { steroidal anti-inflammatory }\end{array}$ \\
\hline 2.4 .1 & $\mathrm{BP}<100 / 60 \mathrm{mmHg}$ & 2.11 & Arterial hypertension \\
\hline 2.4 .2 & $C F>100 \mathrm{bpm}$ & 2.11 .1 & $\mathrm{BP}>150 / 100 \mathrm{mmHg}$ \\
\hline 2.4 .3 & $\mathrm{~T}^{\circ}>37.8^{\circ} \mathrm{C}$ at the time of the appointment & 2.12 & Hypoglycemia \\
\hline 2.4 .4 & Signs of dehydration & 2.12 .1 & Capillary glucose $<$ or $=60 \mathrm{mg} / \mathrm{dl}$ \\
\hline 2.5 & Dyspnea & 2.13 & Cough \\
\hline 2.5 .1 & History of asthma or COPD & 2.13 .1 & $\mathrm{~T}^{\circ}>37.8^{\circ} \mathrm{C}$ at the time of the appointment \\
\hline
\end{tabular}

(The Figure 1 continue in the next page...) 


\begin{tabular}{|cl|ll|}
\hline \multicolumn{5}{|c|}{$\begin{array}{c}\text { Group } 2 \text { (Yellow) - Patients who should be assessed by a doctor in the period between } \mathbf{1 5} \text { and } \mathbf{3 0} \text { minutes } \\
\text { after the nurse's assessment because they present signs and symptoms that could become more serious }\end{array}$} \\
\hline 2.5 .2 & Changes in pulmonary auscultation & 2.13 .2 & BP $<100 / 70 \mathrm{mmHg}$ or CF $>100 \mathrm{bpm}$ \\
2.6 & Abdominal pain & 2.13 .3 & Dyspnea or RF $>20 \mathrm{rpm}$ \\
2.6 .1 & Moderate abdominal pain & $2.13 .4 \quad$ Oxygen saturation $>95 \%$ \\
2.6 .2 & Vital signs within normal limits. & 2.13 .5 & History of hemoptysis \\
2.7 & Neck or back pain & \\
2.7 .1 & Sensory or motor deficit & \\
2.7 .2 & BP<100/70mmHg and CF>100 bpm & \\
2.7 .3 & Previous history of kidney stones, HIV, liver cirrhosis & \\
2.7 .4 & Transplanted or chemotherapy patients & \\
2.7 .5 & Alteration of the sphincter & \\
\hline
\end{tabular}

Figure 2 - Risk classification protocol for Group 2 (Yellow). Campinas, 2010

\begin{tabular}{|c|c|c|c|}
\hline \multicolumn{4}{|c|}{$\begin{array}{l}\text { Group } 3 \text { (Green) - Patients without potential death risks who should be treated } \\
\text { by a doctor from two to four hours after the nurse's assessment }\end{array}$} \\
\hline 3.1 & Special cases & 3.5 & Abdominal pain \\
\hline 3.1 .1 & Age $>60$ years & 3.5 .1 & Light and moderate pain \\
\hline 3.1 .2 & Patients with special needs & 3.5 .2 & Vital signs within normal limits \\
\hline 3.1 .3 & Pregnant women & 3.5 .3 & $\begin{array}{l}\text { Diarrhea, nausea and vomiting (few episodes and in small } \\
\text { quantities) }\end{array}$ \\
\hline 3.2 & Chronic headache & 3.6 & Light to moderate pain \\
\hline 3.2 .1 & Light or moderate pain & 3.6 .1 & Sore throat, earache, among others \\
\hline 3.2 .2 & Onset many days ago & 3.6 .2 & Vital signs within normal limits \\
\hline 3.2 .3 & Absence of motor deficits & 3.7 & Chest pain \\
\hline 3.2 .4 & $\begin{array}{l}\text { Absence of alteration in the level and content of } \\
\text { consciousness }\end{array}$ & 3.7 .1 & Chest pain that affects movement and palpation \\
\hline 3.2 .5 & Vital signs within normal limits & 3.7 .2 & Vital signs within normal limits \\
\hline 3.3 & Diarrhea & 3.7 .3 & History of mild chest trauma \\
\hline 3.3 .1 & Light to moderate abdominal pain & 3.8 & Neck or back pain \\
\hline 3.3 .2 & Nausea and vomiting & 3.8 .1 & Light or moderate pain \\
\hline 3.3.3 & Vital signs within normal limits & 3.8 .2 & Absence of sensory or motor deficits \\
\hline 3.3 .4 & Absence of dehydration signs & 3.9 & High or low gastrointestinal hemorrhage \\
\hline 3.4 & Dyspnea & 3.9 .1 & History of rectal bleeding, melena or hematemesis \\
\hline 3.4 .1 & $\mathrm{RF}, \mathrm{CF}$ and $\mathrm{BP}$ without alterations & 3.9 .2 & Vital signs within normal limits \\
\hline 3.4 .2 & $\begin{array}{l}\text { Absence of alteration in the level and content of } \\
\text { consciousness }\end{array}$ & 3.9 .3 & $\begin{array}{l}\text { History of cirrhosis or liver or colon cancer, use of non- } \\
\text { steroidal anti-inflammatory }\end{array}$ \\
\hline 3.4 .3 & $\begin{array}{l}\text { Pulmonary auscultation without changes or with minor } \\
\text { alterations }\end{array}$ & 3.10 & Cough \\
\hline 3.4 .4 & Absence of fever & 3.10 .1 & Vital signs within normal limits \\
\hline 3.4 .5 & Oxygen saturation $>95 \%$ & 3.10 .2 & Absence of or mild chest pain \\
\hline \multicolumn{4}{|c|}{$\begin{array}{c}\text { Group } 4 \text { (BLUE) - Patients have complaints that should be directed to Primary Healthcare Units. } \\
\text { They will be assessed by a doctor but this assistance is not a priority }\end{array}$} \\
\hline 4.1 & Other chronic cases & 4.3 & Skin wounds \\
\hline 4.1 .1 & Chronic complaints, not sharp & 4.3 .1 & Scabies \\
\hline 4.2 & Light to moderate pain & 4.3 .2 & Eczema \\
\hline \multirow[t]{3}{*}{4.2 .1} & Other complaints of pain lasting more than a week & 4.3 .3 & Other skin wounds \\
\hline & & 4.4 & Patients seeking the emergency unit for: \\
\hline & & 4.4.1 & $\begin{array}{l}\text { Dressings/removal of stitches/change of probe and medical } \\
\text { prescriptions / administration of continuous use medication }\end{array}$ \\
\hline
\end{tabular}

Figure 3 - Risk classification protocol: Groups 3 (Green) and 4 (Blue). Campinas, SP, Brazil, 2010

Data were entered into the program Excel and analyzed by the Statistical Office of the institution where the authors are based, using the program Statistical Analysis System (SAS), version 9.2. For the reliability test, the Weighted Kappa Coefficient was used and scores over 0.75 showed excellent agreement, below 0.40 , low agreement, and between 0.40 and 0.75 , moderate agreement ${ }^{(16)}$.

The study was approved by the Research Ethics Committee of the institution under number 1114/2008. 


\section{Results}

In relation to the organization criterion at the validation stage, most of the 35 items assessed had $100.0 \%$ agreement among the specialists. Concerning the coverage criterion, 21 items were assessed with $100.0 \%$ agreement, four had $83.3 \%$, seven had $66.6 \%$, two had $50.0 \%$ and one had $33.3 \%$. Therefore, 32 of the 35 items showed agreement rates equal or over $66.6 \%$.

As for objectivity, 14 items had $100.0 \%$, five had $83.3 \%$, five others had $66.6 \%$, eight had $50.0 \%$, two had $33.3 \%$ and one $16.7 \%$ agreement rate. In relation to relevance, the following results were reached: 11 items had $100 \%$; 11 others, $83.3 \%$; eight, $66.6 \%$ and five had $50.0 \%$ agreement rate.

Based on these results, and taking into account the specialists' proposals, the items with higher percentage of disagreement were worked on. The version of the modified protocol after the committee's meeting was submitted to reliability assessment.

At the reliability stage, it can be noted that the observer-researcher and the obs-1 agreed in relation to the risk classification of the ten assessed patients. Concerning the obs- 2 and 4 , there were eight agreements and nine with the obs-3.

Despite obs- 2 and 4 having the same number of agreements in the assessments, the Kappa Coefficients were different to both of them ( 0.79 and 0.60 , respectively), since there was a bigger difference in the priority classification between the researcher and the obs-4.

Although there was no disagreement in relation to the priority of assistance in the risk classification between the observer-researcher and the obs-1, there was disagreement in relation to the classification item in three cases; concerning the obs- 2 and 4 this disagreement occurred in two cases and with the obs-3, in one case.

It could also be noted that, for each assistance priority, the number of agreements in the assessments varied, as follows: $11 / 40$ (27.5\%0 yellow, 20/40 (50.0\%) green and $4 / 40(10.0 \%)$ blue, with 0.81 weighted Kappa Coefficient. The disagreements in the assessments were $5 / 40(12.5 \%)$.

\section{Discussion}

With respect to content validity, 31 of the 35 items were considered organized and, in relation to relevance, 32 items had an agreement rate of $66.6 \%$ or over among the specialists, which showed that the protocol is organized and capable of covering a diversity of cases treated in the unit.

As for objectivity, 24 items had agreement equal or over $66.6 \%$ and this suggests that the protocol had many sub-items for each complaint, causing confusion during the assessment and consequently a change in the prioritization of assistance. After the changes in the protocol based on individual and the committee's suggestions, it was noted that the reliability stage reached an excellent agreement rate.

Concerning relevance, the assessment of the specialists was positive, since the assessment of 30 items had percentages equal or over $66.6 \%$. It was observed that the specialists understood most of the items and that the content can be understood by the nurses. It is suggested that the instrument has content validity.

Among the assistance priorities, there were more suggestions of change after the meeting in relation to red and yellow. The removal of items that would not make any difference in the assessment of the patients was positive, being only those considered extremely important kept.

There was an attempt to standardize the items that covered scores of vital signs (SSVV), taking into account: increased blood pressure (PA) if $>140 / 90 \mathrm{mmHg}$, PA decreased if $<100 / 70 \mathrm{mmHg}$, increased respiratory rate (FR) if $>20 \mathrm{rpm}$, tachycardia if heart rate (FC) $>100 \mathrm{bpm}$ and fever if temperature $(T)>37.8^{\circ} \mathrm{C}$.

In the parameters adopted for the PA, two observers had contrary positions because they understood that these scores may overestimate the complaint of some patients, increasing the number of yellow patients and causing difficulties in the assistance. However, the Brazilian Guidelines of Hypertension was used as a basis ${ }^{(17)}$.

The chest pain item was greatly changed by the observers. In the red group, the sub-items that are important for the early identification of pain in cases of acute coronary syndrome, aortic and pneumothorax dissection were kept, since they need urgent care, according to the recommendations of the guidelines for the Treatment of Acute Myocardial Infarction with ST-Segment Elevation(18). In the yellow and green groups, the sub-items that did not need immediate care remained, such as the potentially risky (Group 2 - yellow) and those typical to other pains, such as muscular ones (Group 3 - green).

Concerning arterial hypertension, the sub-items typical of emergency hypertension were kept in the red, since there is risk of serious and imminent death organic 
damage in these cases $^{(18)}$. In Group 2, the patient is hypertensive, but without the risk of acute organic damage. In the item cardiorespiratory arrest (PCR), the sub-items that identify the event were kept, according to the International Guidelines about PCR ${ }^{(19)}$.

Regarding chronic headaches, symptoms identifying the emergencies such as head trauma, subarachnoid hemorrhage, subdural hematoma and meningitis remained in the red. The cases of tension headaches, migraine and hypertension remained in the yellow, and mild and not disabling chronic headaches in the green. According to a Brazilian study(20), migraine was responsible for $56.4 \%$ of the cases of chronic headache in patients who sought the emergency services and, among these, $77.0 \%$ were primary headache, being patients referred to the treatment of the pain and not to diagnostic procedures.

In the motor deficit item, the sub-item that identifies cases of ischemic or hemorrhagic stroke (AVC) remained. The deficit time defined by the specialists for the red group was less than three hours, since this is the time appointed for the performance of thrombolysis for ischemic stroke ${ }^{(21)}$.

Dyspnea can be caused by various illnesses: asthma, chronic obstructive pulmonary disease (DPOC) ${ }^{(22)}$, hypertensive crisis(17), infections, among others. In the red, the typical symptoms of acute respiratory failure were kept; in the yellow, those associated with the cases of DPOC and asthma without signs of respiratory insufficiency and, in the green, those that do not pose risk of clinical deterioration.

As for reliability, the agreement rate between the observer-researcher and the obs-1 was excellent for all the risk classification categories, showing a good understanding of the protocol. Despite the classifications having been consistent between them, there was disagreement in the classification item of three cases, but without change in the priority of assistance or risks to the patient. For example, in one of the assessments, the priority of assistance was considered yellow by both of them, the complaint being mental confusion with alteration of the SSVV. The observer-researcher considered the alteration of mental status item (2.2) and the obs-1, the alteration of the SSVV (2.1) This example shows that the same complaint may be interpreted differently and have the same priority.

The results of the assessments between the observer-researcher and the obs-1 show that knowledge and experience are key factors when deciding what type of priority the patient is, and this fact is also pointed out in an Australian study(23).

Between the observer-researcher and the obs2 and 3, the agreement rate was also excellent. With the obs-2, there was disagreement in the item within the same classification and two disagreements in the assistance priority. The case showing disagreement of items, the complaint was dysuria/low back pain with alteration of blood pressure. The researcher considered the alteration of SSVV item (2.1) and the obs-2, the blood pressure item (2.11), which resulted in the same assistance priority.

However, in relation to disagreement concerning the priority, the patient was classified green by the researcher and blue by the obs-2, the complaint being earache lasting for 15 days. The researcher considered the mild to moderate pain with normal SSVV item (3.6) and the obs-2, the mild to moderate pain lasting for more than a week item (4.2). The differences concerning the assistance prioritization did not bring any risks to the patient, since they are not emergency complaints.

Another assessment in which there was disagreement concerning the priority, the patient was classified yellow by the researcher and blue by the obs2 . The complaint was pain in the upper limb lasting for a week. Although, at first, it seemed to be a serious error on the part of one of the raters, it is noteworthy that a slight change in heart rate (106 bpm) led the researcher to classify the patient in the alterations of SSVV item (2.1), which is a parameter that was not considered by the obs-2, who classified the patient in the mild to moderate pain lasting for more than a week (4.2). Therefore, there is a need to review the cut-off scores of the SSVV.

Between the researcher and the obs-3, there were two disagreements in the item within the same classification and one disagreement related to the priority of assistance. For the same classification but different items, one of the cases was classified yellow, the patient's complaint being fever and myalgia with $\mathrm{T}=38^{\circ} \mathrm{C}$ e $\mathrm{FC}=124 \mathrm{bpm}$. The researcher considered the fever item (2.9) and the obs-3, alteration of SSVV (2.1), showing appropriate understanding of the protocol. In the second case, blue, in which the complaint was earache lasting for two months, the researcher used the mild to moderate pain lasting for more than a week item (4.2) and the obs-3 used the chronic complaint item (4.1). In this case, it may be necessary to specify what chronic complaint means, although this has not compromised the assistance prioritization. 
As for the disagreement in relation to the assistance priority, the observer-researcher classified the patient as blue and the obs- 3 as green, the complaint being chest pain after physical exercise. The blue priority classification was due to the fact that, at the time of the assessment, the patient did not present any symptoms. The obs-3 classified the patient in the chest pain with normal SSVV item (3.7). There is a need to include one more item in the protocol: asymptomatic patient at the time of assessment.

With the obs-4, there were no disagreements in the item within the same classification, but two disagreements in relation to assistance priority. The researcher used the yellow priority in one of the classifications and the obs-4 used the green one. The complaint was myalgia, fever and headache. The researcher considered the alterations of SSVV item (2.1), since the FC=109bpm; the obs-4 classified the user in the mild to moderate pain item (3.6), but did not take into account the FC alteration, as did the obs-2.

The findings show that extensive training of the nurses to carry out risk classification and applicability/ assessment of the protocol will be required to improve its specificity. The training of nurses is shown to be extremely necessary, since studies ${ }^{(22-23)}$ showed that, the higher the professional qualification and greater the number of hours practicing risk classification, the better the results will be in the prioritization of assistance.

It is believed that the training of all nurses before the implementation of the protocol in the Unit under study will be required. Furthermore, the application of the protocol more often will allow its proper knowledge and getting used to using it.

The findings confirm the need to review the cutoff scores of vital parameters, which was previously suggested, and bring an alert to nurses to consider important subtle changes that may progress to severe hemodynamic changes while the patient awaits medical care.

It is important to note that the observers who had lower Kappa Coefficient, and therefore lower agreement in the classification, had less time working at the UER and with risk classification, while those who had higher coefficient performed this activity for longer. This fact suggests that the greater the experience of the professional in the activity, the smaller the chances of disagreements, as shown in an American study ${ }^{(24)}$.

Although there are differences in the experience with risk classification, and the training provided by the researcher has been brief, the protocol reliability was excellent, which shows that it is clear and objective, and possible to be applied to the Unit's reality. Another important factor is the need to exercise its use, to improve the application skills and avoid errors, and also be able to point out difficulties and suggest improvements.

\section{Conclusion}

The assessment and risk classification protocol developed showed content validity and, after the suggested changes were made, there were excellent results concerning reliability. The assistance flow chart was shown to be easy for the nurses to use, and important to help the search for the complaint in each priority.

The use of the protocol and the flow chart developed in this research was shown to be easy for the nurses to use, with satisfactory results in risk classification, which will facilitate the implementation process.

Further studies with larges samples of patients will be required to assess the impact of the use of this protocol in other Emergency Units. It is believed that its use will bring a number of benefits for the users and the team, since there will be standardization of the assistance, reduction of the risks caused to patients during the waiting period and more security for those using it. The use of this protocol more often will point out to possible problems that might be modified to suit the reality.

\section{References}

1. Bullard MJ, Unger B, Spence J, Grafstein E, CTAS National Working Group. Revisions to the Canadian Emergency Department Triage and Acuity. CJEM. 2008;10(2):136-42.

2. O'Dwyer G, Matta IEA, Pepe VLE. Avaliação dos serviços hospitalares de emergência do estado do Rio de Janeiro. Ciênc Saúde Coletiva. 2008; 13(5):1637-48.

3. Ministério da Saúde (BR). Documento base para gestores e trabalhadores do SUS [Internet]. 2008. [acesso 17 fev 2013]. Disponível em: http://bvsms. saude.gov.br/bvs/publicacoes/humanizasus_ gestores_ trabalhadores_sus_4ed.pdf

4. Ministério da Saúde (BR). Boas práticas de humanização na atenção e na gestão do Sistema Único de Saúde: acolhimento e classificação de risco na emergência do Hospital Nossa Senhora da Conceição [Internet]. 2006. [acesso 17 fev 2013]. Disponível em: http://portal. saude.gov.br/portal/arquivos/pdf/GHC_02-10.pdf 
5. Beveridge R, Clarke B, Janes L, Savage N, Thompson

J, Dodd G, et al. Implementation Guidelines for The Canadian Emergency Department. Triage \& Acuity Scale (CTAS). Endorsed by the Canadian Association of Emergency Physicians (CAEP), the National Emergency Nurses Affiliation of Canada (NENA), and L'association des médecins d'urgence du Québec (AMUQ). Canadá; 1998.

6. Gilboy N, Travers D, Wuerz R. Emergency nursing at the millennium. Re-evaluating triage in the new millennium: a comprehensive look at the need for standardization and quality. J Emerg Nurs. 1999;25:468-73.

7. Conselho Federal de Enfermagem (BR). Resolução no 423/2012. [Internet]. [acesso 12 jun 2013]. Disponível em: http://www.novo.portalcofen.gov.br.

8. Oliveira GN, Silva MFN, Araujo IEM, Carvalho MA Filho. Profile of the Population Cared for in a Referral Emergency Unit. Rev. Latino Am. Enfermagem. 2011;19(3):548-56.

9. Freitas P. Triagem no Serviço de Urgência/emergência: Grupo de Triagem de Manchester. Portugal: Grupo Português de Triagem - BMJ Publishing Group; 1997. 154 p. 10. Guidelines for implementation of the Australasian Triage Scale (ATS) in Emergency Departments. Australasian College for Emergency Medicine; 2001.

11. Michael J, Bullard MJ, Unger B, +Spence J, Grafstein E, CTAS National Working Group. Revisions to the Canadian Emergency Department Triage and Acuity Scale (CTAS) adult guidelines. CJEM 2008;10(2):136-42.

12. Gilboy N, Tanabe P, Travers DA, Rosenau AM, Eitel DR. Emergency Severity Index, Version 4: Implementation Handbook. Rockville, MD: Agency for Healthcare Research and Quality; May 2005.

13. Projeto acolhimento no Pronto-Socorro do Hospital Municipal Dr. Mário Gatti [Internet]. Campinas (SP). [acesso 15 abril 2012]. Disponível em: http://www. saude.sp.gov.br/content/ii_oficina_acolhimento. mmp 14. Mafra AA, Martins $P$, Belezia $B$, Shimazaki ME, Barbosa YR, Rates SMM, et al. Acolhimento com classificação de risco no pronto-socorro do Hospital Municipal Odilon Behrens de Belo Horizonte [Internet]. Belo Horizonte; 2006. [acesso 15 abril 2012]. http://www.saude.sp.gov.br/resources/ humanizacao/docs/revista_hob_mai06_versao_5.pdf
15. Ministério da Saúde (BR). Secretaria Executiva. Núcleo Técnico da política Nacional de Humanização. HumanizaSus: Acolhimento com avaliação e classificação de risco: um paradigma ético-estético no fazer em saúde. Brasília; 2004.

16. Fleiss JL. Statistical Methods for Rates and Proportions. 2ed. Nova Iorque: John Wiley \& Sons; 1981.

17. Sociedade Brasileira de Cardiologia/Sociedade Brasileira de Hipertensão/Sociedade Brasileira de Nefrologia. VI Diretrizes Brasileiras de Hipertensão. Arq Bras Cardiol 2010; 95(supl.1):1-51

18. Piegas LS, Feitosa G, Mattos LA, Nicolau JC, Rossi Neto JM, et al. Sociedade Brasileira de Cardiologia. Diretriz da Sociedade Brasileira de Cardiologia sobre Tratamento do Infarto agudo do Miocárdio com Supradesnível do Segmento ST. Arq Bras Cardiol. 2009; 93(6supl.2):e179-e264.

19. Nolan JP, Hazinski MF, Billi JE, Boettiger BW, Bossaert $L$, Caen AR, et al. Part 1: executive summary: 2010 International Consensus on Cardiopulmonary Resuscitation and Emergency Cardiovascular Care Science With Treatment Recommendations. Resuscitation. 2010;81:e1-e25

20. Bigal ME, Bordini CA, Speciali JG. Tratamento da cefaléia em uma unidade de emergência da cidade de Ribeirão Preto. Arq Neuropsiquiatr. 1999;57(3-B):813-8. 21. Ministério da Saúde (BR). Secretaria de Atenção à Saúde. Departamento de Atenção Especializada. Coordenação Geral de Urgência e Emergência. Programa Nacional de Atendimento à doença vascular aguda. Brasília; 2009.

22. Cioffi J. Education Triage decision making: educational strategies. Accid Emerg Nurs. 1999;7:106-11.

23. Fry M, Burr G. Current triage pratice and influences affecting clinical decision- making in emergency departaments in NSW, Australia. Accid Emerg Nurs. 2001;9:227-34. 24. Derlet RW, Kinser D, Ray L, Hamilton B, McKenzie J. Prospective identification and triage of nonemergency patients out of an emergency department: a 5-year study. Accid Emerg Nurs. $1995 ; 25(2): 215-23$.

Received: Mar. $10^{\text {th }} 2013$ Accepted: Dec. $10^{\text {th }} 2013$

\section{Erratum}

\section{Issue v22n2, page 218}

For

Eliete Boaventura Bargas ${ }^{6}$

${ }^{6} \mathrm{PhD}$, Associate Professor, Faculdade de Enfermagem, Universidade Estadual de Campinas, Campinas, SP, Brazil.

Read

Eliete Boaventura Bargas ${ }^{6}$

${ }^{6}$ MSc, RN, Hospital de Clínicas, Universidade Estadual de Campinas, Campinas, SP, Brazil. 